\title{
Diagnostic reliability of different RT-PCR protocols for the detection of bluetongue virus serotype 14 (BTV-14)
}

\author{
Anna Orłowska, Jan F. Żmudziński, Marcin Smreczak, \\ Paweł Trębas, Anna Marzec \\ Department of Virology, National Veterinary Research Institute, 24-100 Pulawy, Poland \\ anna.orlowska@piwet.pulawy.pl
}

Received: July 11, $2017 \quad$ Accepted: December 4, 2017

\begin{abstract}
Introduction: The reverse transcription polymerase chain reaction (RT-PCR) is one of the most extensively used methods for identification of animals infected with bluetongue virus (BTV). There are several RT-PCR protocols published and several real-time RT-PCR (rtRT-PCR) commercial kits available on the market. Because Poland faced BTV-14 infection in 2012, different protocols were implemented in the country to confirm the RT-PCR results positive for this virus. The article presents a comparative study of several RT-PCR protocols and discusses their diagnostic reliability and applicability. Material and Methods: Six rtRT-PCR/RT-PCR protocols were compared for the laboratory diagnostic of fourteen BTV-14 isolates circulating in Poland in 2012-2014. Results: All 14 isolates were positive in the protocols of Shaw et al. (18), a commercial LSI NS3 kit, and Eschbaumer et al. (5). Four out of fourteen BTV-14 isolates gave positive results in Hoffmann's 2 and 6 protocols and none of the 14 isolates yielded positive results in Maan et al. (8) method. Phylogenetic study of a short fragment of $450 \mathrm{nt}$ of BTV segment 2 (258-696 positions) revealed 100\% identity within Polish variants and with Russian and Spanish isolates. Conclusion: The paper points to the possible false negative results in the diagnosis of BTV infections depending on the protocol used.
\end{abstract}

Keywords: bluetongue, typing, genetic variability, Poland.

\section{Introduction}

Bluetongue (BT) is an anthropod-borne viral disease caused by the bluetongue virus (BTV) belonging to the Orbivirus genus of the Reoviridae family. The disease is economically important, affecting domestic and wild ruminants especially sheep, goats, and cattle $(3,4)$. Primarily the disease has occurred in tropical regions of the world. Significant changes in the distribution of BTV have been recorded since 1998, and previously exotic serotypes (1, 2, 3, 4, 9, and 16) have spread throughout Mediterranean Europe causing BT outbreaks in ruminants (24). In 2006, BTV serotype 8 emerged in Northern Europe and spread rapidly through Belgium, the Netherlands, France, and Germany (3, 7, 22-24). BTV-14 was identified for the first time in Northeastern Europe in the Smolensk region of Russia in 2011. In 2012 national bluetongue monitoring programmes and premovement animal testing reported BTV-14 in
Lithuanian cattle imported to Spain, Poland, Latvia, and Estonia $(10,12,13)$.

The BTV genome, consisting of approximately 19,200 base pairs, is composed of ten linear segments of double stranded RNA (dsRNA) coding 11 distinct proteins (8). Seven are structural viral proteins (VP1 to VP7) and the remaining four (NS1 to NS4) are nonstructural proteins (15). The majority of BTV proteins are highly conserved, exemplified by the more than $75.9 \% \mathrm{nt} / 81.2 \%$ aa identity shown for segment 10 of BTV coding NS3 protein involved in virus exit from infected cells. Therefore, this segment is the target most frequently used for BTV detection in animals.

Seg-2 is the highly variable region of the BTV genome coding VP2, the outer capsid protein involved in cell attachment and entry. VP2 is particularly relevant in diagnosis due to the epitope responsible for virus neutralisation as well as serotype determination (2). Serological characterisation of BTV is often complicated by cross-neutralisation among different 
serotypes (4), therefore, conventional serological methods are replaced with molecular techniques. Phylogenetic analyses of Seg-2 of multiple BTV isolates has separated BTV isolates into 27 distinct clades formed in two major "topotypes" (eastern and western) and several additional groups (11).

Genetic variability of viruses is a natural evolutionary process comprising mainly genome recombination, gene reassortment, and nucleotide substitution. Viruses with segmented RNA, of which BTV is an example, can exchange genetic material generating new variants when co-infecting a single host, and these new serotypes emerging as a result of genome mutation can cause difficulty in molecular diagnosis. Nucleotide sequence variability within and between different BTV serotypes hinders the designing of one universal set of primers that could cover the plethora of variants emerging in the field. There are a few papers describing molecular methods for BTV detection based on segments 1,2 , or 7 of the BTV genome $(1,5,8,18)$. Besides these methods there are commercial kits on the market which can be used for BTV typing (e.g. the LSI VetMAX Bluetongue Virus NS3 kit and the Virotype BTV Plus real-time RT-PCR test kit). However, some molecular-based techniques can produce false or confusing results due to the high genetic variation of BTV isolates.

The paper presents the reliability of a few molecular protocols applied for detection and identification of BTV-14 isolates collected in Poland between September 2012 and October 2014. It also briefly discusses the phylogenetic variability of Polish BTV-14 isolates.

\section{Material and Methods}

Samples. The study involved 14 EDTA blood samples described in Table 1 originating from cattle, sent to the National Veterinary Research Institute in Puławy, Poland for BTV diagnosis. The presence of viral RNA was examined in the sample as a follow up to seropositive results in BT ELISA.

RNA extraction and denaturation. Total RNA was extracted with a commercial QIAmp Viral RNA Mini Kit (Qiagen, Germany), according to the manufacturer's instructions, from $140 \mu \mathrm{L}$ noncoagulated blood samples. Extracted dsRNA was exposed directly to heat denaturation at $100^{\circ} \mathrm{C}$ for 5 min followed by rapid cooling on ice and then used immediately for RT-PCR or stored frozen at $-20^{\circ} \mathrm{C}$.

rtRT-PCR. The commercially available LSI VetMAX Bluetongue Virus NS3 kit (LifeTechnologies, Thermo Fisher Scientific, USA) was used as the first step. To verify the results of the LSI test, the rtRT-PCR assay described by Shaw et al. (18) was applied.

In order to serotype BTV positive samples, rtRTPCR procedures designed and provided by Dr. Bernd Hoffmann from the Friedrich Loeffler Institute (FLI) in
Germany were used. Dual procedures are performed at the FLI for detection of animals suspected of having BTV-14 infection. The protocol consists of two duplex rtRT-PCR methods (mix 2 and mix 6), both dedicated to BTV-14 detection with $\beta$ actin/EGFP as internal controls. A mixture of $5 \mu \mathrm{L}$ of RNA template and $2 \mu \mathrm{L}$ of the mix of BTV primers and probe after heat denaturation at $95^{\circ} \mathrm{C}$ for $3 \mathrm{~min}$ were added to reaction mixture containing $12.5 \mu \mathrm{L}$ of master mix, $2 \mu \mathrm{L}$ of mix of primers for $\beta$ actin/EGFP, $1 \mu \mathrm{L}$ of enzyme mix, and $2.5 \mu \mathrm{L}$ of RNAse-free water. The reactions were carried out in a Stratagene Mx3005P thermocycler (Thermo Fisher Scientific, USA) with the following programme: 1 cycle of reverse transcription at $45^{\circ} \mathrm{C}$ for $10 \mathrm{~min}, 1$ cycle of $95^{\circ} \mathrm{C}$ for $10 \mathrm{~min}$ followed by 42 cycles of $95^{\circ} \mathrm{C}$ for $15 \mathrm{~s}, 56^{\circ} \mathrm{C}$ for $20 \mathrm{~s}$, and $72^{\circ} \mathrm{C}$ for $30 \mathrm{~s}$.

RT-PCR and sequencing. Two methods of RTPCR for the detection of BTV-14 described previously by Eschbaumer et al. (5) and Maan et al. (8) were used. Since the procedure published by Maan et al. (8) had failed in detection of Polish BTV-14 isolates, the method was optimised by increasing the annealing temperature from 49 to $55^{\circ} \mathrm{C}$. The remaining parameters, including reagent concentrations, temperature, and time of cycling, were as described previously (8).

After separation in 2\% agarose gel, the amplicons obtained with the method of Eschbaumer et al. (8) were subjected to sequencing which was performed in both directions in an ABI PRISM 310 Genetic Analyzer automated sequencer (Applied Biosystems, Thermo Fisher Scientific, USA) using a BigDye Sequencing Kit (Applied Biosystems) with GeneScan analysis software (Applied Biosystems).

Phylogenetic analysis. Nucleotide sequences of 14 positive for BTV-14 samples were aligned with Clustal W multiple alignment software based on the $450 \mathrm{bp}$ region of Seg-2. To determine phylogenetic relationships, Polish BTV-14 isolates were compared to reference sequences (available in the GenBank database and described briefly in Table 1). A phylogenetic tree was generated using the neighbour joining (NJ) method with the Kimura 2-parameter mode and bootstrapped on the set of 1,000 replicates with Mega software v. 4.1 (21).

\section{Results}

rtRT-PCR. All blood samples included in the study were positive in rtRT-PCR with the LSI NS3 kit (Ct 25.96 to 36.95) designed to detect BTV Seg-10 and confirmed by the method of Shaw et al. (18) (Ct values ranged from 25.5 to 35.68 ) targeting BTV Seg-1. Four out of fourteen BTV-14 positive samples were positive with Hoffmann's protocols, either with mix 2 or mix 6 . Ct values were slightly higher when mix 2 was used (29.0 to 30.26$)$ than when mix 6 was applied (30.35 to 
35.48). The remaining 10 samples were negative with both protocols (Table 2).

RT-PCR and phylogenetic analysis. The application of the RT-PCR method described by Maan et al. (8) has revealed no products of expected size. Reoptimisation of the method, i.e. increasing the annealing temperature to $55^{\circ} \mathrm{C}$, resulted only in nonspecific product generation, approximately $600 \mathrm{bp}$, in 6 out of 14 samples. Viral RNA in all blood samples was detected by the RT-PCR method described by
Eschbaumer et al. (5). The results are presented in Table 1. RT-PCR products of BTV Seg-2 of the expected $450 \mathrm{bp}$ size were subjected to sequencing. Multiple sequence alignment revealed 100\% nucleotide sequence identity of the Seg-2 of all Polish BTV isolates and BTV-14 isolates collected in South Africa, Spain, and Russia. Fig. 1 demonstrates the phylogenetic relationships of the dataset $(n=9)$ of BTV Seg-2 sequences (KY075918-KY075926) using the NJ method.

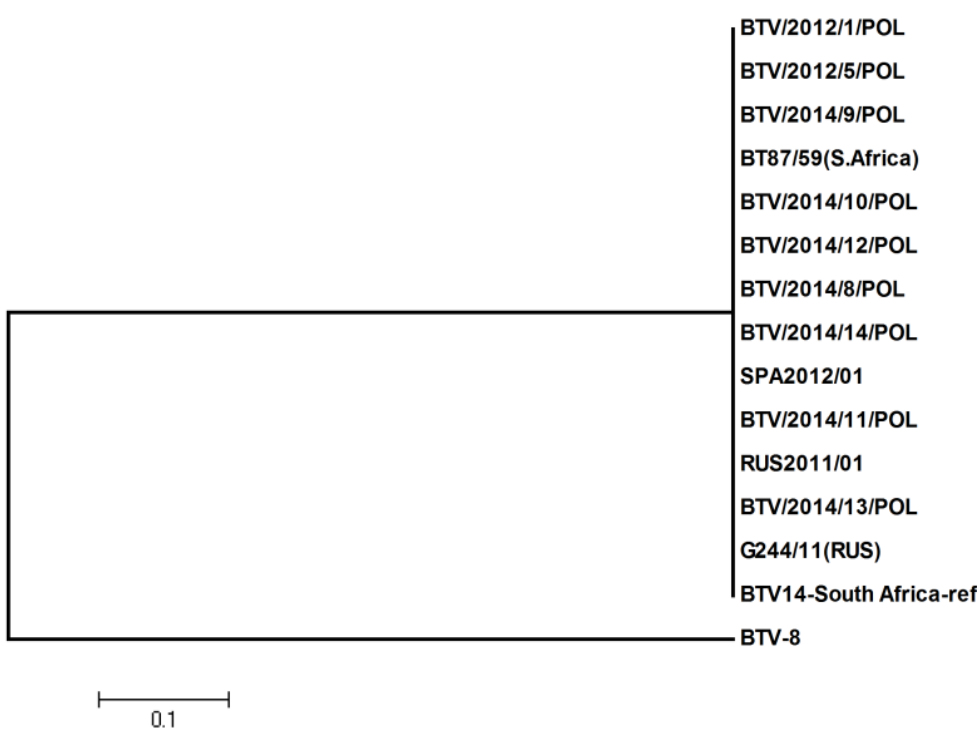

Fig. 1. The phylogenetic tree comparing the Polish BTV-14 isolates with the reference BTV-14 strains. The phylogenetic analysis was conducted with the NJ method. Bootstrap values were obtained for 1,000 replicates. The BTV-8 strain was used as the outgroup

Table 1. Description of BTV isolates used in the present study. POL means Poland

\begin{tabular}{|c|c|c|c|}
\hline Isolate & Collection data & Origin & GenBank accession number \\
\hline $\mathrm{BTV} / 2012 / 1 / \mathrm{POL}$ & 15.09 .2012 & Sokółka (POL) & KY075919 \\
\hline $\mathrm{BTV} / 2012 / 2 / \mathrm{POL}$ & 15.09.2012 & Sokółka (POL) & - \\
\hline $\mathrm{BTV} / 2012 / 3 / \mathrm{POL}$ & 15.09.2012 & Sokółka (POL) & - \\
\hline BTV/2012/4/POL & 15.09.2012 & Sokółka (POL) & - \\
\hline $\mathrm{BTV} / 2012 / 5 / \mathrm{POL}$ & 17.09.2012 & Suwałki (POL) & KY075924 \\
\hline $\mathrm{BTV} / 2012 / 6 / \mathrm{POL}$ & 17.09.2012 & Augustów (POL) & - \\
\hline $\mathrm{BTV} / 2012 / 7 / \mathrm{POL}$ & 17.09.2012 & Augustów (POL) & - \\
\hline $\mathrm{BTV} / 2014 / 8 / \mathrm{POL}$ & 27.01 .2014 & Białystok (POL) & KY075918 \\
\hline $\mathrm{BTV} / 2014 / 9 / \mathrm{POL}$ & 27.01 .2014 & Białystok (POL) & KY075922 \\
\hline $\mathrm{BTV} / 2014 / 10 / \mathrm{POL}$ & 25.10 .2014 & Grajewo (POL) & KY075923 \\
\hline BTV/2014/11/POL & 29.10 .2014 & Olecko (POL) & KY075920 \\
\hline $\mathrm{BTV} / 2014 / 12 / \mathrm{POL}$ & 29.10 .2014 & Olecko (POL) & KY075925 \\
\hline BTV/2014/13/POL & 29.10 .2014 & Mrągowo (POL) & KY075926 \\
\hline BTV/2014/14/POL & 29.10 .2014 & Giżycko (POL) & KY075921 \\
\hline Rus2011/01 & 09.2011 & Russia: Smolensk-Galloway & KP821096 \\
\hline BT87/59 (S. Africa) & - & South Africa & JX272480 \\
\hline SPA2012/01 & 08.2012 & Spain (cow imported from Lithuania) & KP821097 \\
\hline G244/11(RUS) & 2011 & Russia & KR233814 \\
\hline BTV14-SouthAfrica-ref & - & - & AJ585135 \\
\hline BTV-8 & 02.2011 & Brazil & KM110785 \\
\hline
\end{tabular}


Table 2. Comparison of the results obtained with different RT-PCR based amplification techniques

\begin{tabular}{|c|c|c|c|c|c|c|}
\hline \multirow{2}{*}{ Sample } & \multicolumn{4}{|c|}{ rtRT-PCR (Ct result) } & \multicolumn{2}{|c|}{ RT-PCR } \\
\hline & LSI NS3 Kit & $\begin{array}{l}\text { Shaw } \\
\text { et al. (18) }\end{array}$ & Hoffmann mix 2 & Hoffmann mix 6 & Maan et al. (8) & $\begin{array}{l}\text { Eschbaumer } \\
\text { et al. (5) }\end{array}$ \\
\hline $\mathrm{BTV} / 2012 / 1 / \mathrm{POL}$ & 31.66 & 33.3 & negative & negative & non-specific product & positive \\
\hline $\mathrm{BTV} / 2012 / 2 / \mathrm{POL}$ & 31.02 & 32.2 & negative & negative & negative & positive \\
\hline $\mathrm{BTV} / 2012 / 3 / \mathrm{POL}$ & 36.95 & 30.6 & negative & negative & negative & positive \\
\hline BTV/2012/4/POL & 26.05 & 25.5 & 30.35 & 29.0 & non-specific product & positive \\
\hline BTV/2012/5/POL & 25.96 & 31.2 & 32.75 & 29.38 & negative & positive \\
\hline BTV/2012/6/POL & 27.87 & 27.87 & 33.09 & 29.32 & non-specific product & positive \\
\hline BTV/2012/7/POL & 26.53 & 26.53 & 33.94 & 29.88 & non-specific product & positive \\
\hline BTV/2014/8/POL & 29.18 & 33.1 & negative & negative & non-specific product & positive \\
\hline BTV/2014/9/POL & 30.08 & 34.2 & negative & negative & non-specific product & positive \\
\hline BTV/2014/10/POL & 30.08 & 33.46 & negative & negative & negative & positive \\
\hline BTV/2014/11/POL & 29.69 & 34.24 & negative & negative & negative & positive \\
\hline $\mathrm{BTV} / 2014 / 12 / \mathrm{POL}$ & 30.54 & 33.99 & negative & negative & negative & positive \\
\hline BTV/2014/13/POL & 33.4 & 35.41 & negative & negative & negative & positive \\
\hline BTV/2014/14/POL & 32.62 & 35.87 & negative & negative & negative & positive \\
\hline
\end{tabular}

\section{Discussion}

In field diagnosis of cases, monitoring of regional epidemiological status, and control of the disease, molecular detection of BTV is usually based on the conserved region of the viral genome, but the serotype can only be ascertained from a highly variable region like Seg-2 (8). A variety of BTV serotypes/variants can circulate in the same endemic region $(13,16)$ and coinfections by different types may significantly influence the laboratory diagnosis of BT and in consequence the control of the disease. Genomic sequence variation within BTV serotypes isolated from the particular topotype or different geographical regions makes it difficult to design universal primer sets for PCR-based amplification techniques $(8,14)$. Therefore, laboratories performing molecular detection of BTV have to be aware of the limitations resulting from the RT-PCR protocols used. In the case of the Polish samples, the application of the RT-PCR method described by Maan et al. (8) yielded no products of expected size. Despite the fact the method applies three pairs of primers covering almost the whole Seg-2 of BTV-14 (107 nt-2142 nt position), the Polish BTV-14 isolates were not detected. The primers in the method of Maan et al. were developed based on the nucleotide sequence of isolates collected from sheep in the USA (Marion County, Florida) in 2003 and were successfully tested for amplification of Seg-2 BTV-14 strains belonging to a "Western" topotype. Nevertheless, Polish BTV-14 isolates previously characterised as "Western" topotypes were not detected when this method was used.

Positive results for BTV-14 detection in all blood samples were obtained with the RT-PCR assay developed by Eschbaumer et al. (5). Shaw et al. (18) presented rt-RT-PCR protocol and the LSI NS3 commercial kit. Only 4 of 14 samples positive in the above protocols were positive in the Hoffmann mix 2 and 6 protocols. These comparative results of various
RT-PCR protocols clearly indicate how important for monitoring and control of BTV infection the results from diagnostic laboratories can be. Probably, the discrepancy in the detection of Polish isolates by different PCR protocols listed in Table 1 signifies intratype sequence variation within primer from annealing applied by the different protocols.

Our study shows that although BTV detection based on the conserved region of the genome gives reliable results, BTV typing can produce more confusing outcomes. There are many primers designed for BTV-14 typing but there is still a need to improve the detection methods, especially for the niche isolates circulating in restricted areas. Thus, the general conclusion of the study is that false negative typing results generated by one method or protocol should be verified by other protocols. It should be also remembered that new BTV serotypes are still appearing $(6,17,20)$. Therefore, laboratory diagnosticians performing BTV diagnosis and veterinarians making administrative decisions, e.g. on consignments of animals entering the country, should be aware of the limitations of the RT-PCR protocols used by the laboratory for the detection of BTV-infected animals.

Multiple sequence alignment of the $450 \mathrm{bp}$ nucleotide sequence fragment within Seg-2 of BTV-14 has revealed $100 \%$ nucleotide sequence identity of the Seg-2 of all 14 Polish isolates, which suggests the circulation of one BTV-14 serotype. The high homology between Polish BTV-14 isolates and the vaccine strain containing BTV-14 seems to confirm previous suggestions of the spread of the attenuated BTV-14 vaccine strain in the field $(10,13)$. BTV isolates closely related to this vaccine strain or one of the other two (BTV-6 and BTV-11) were detected in Northern Europe, although their route of entry is still unclear. These live attenuated vaccine strains are not excluded from the rapid and progressive reassortment taking place between co-circulating BTV strains, as phylogenetic analysis of strains of European and North 
African origin has shown (9). Reassortment between two serologically unrelated BTV strains is flexible and can involve any genome segment (19).

A close relationship of Polish BTV-14 isolates was shown with BTV-14 strains diagnosed in Russia and Spain (in the case of a calf imported from Lithuania). Regarding the close relationship of Polish, Russian, and Spanish BTV-14 isolates, plotting the time of their appearance may suggest the direction of BTV-14 transmission in Europe. As we mentioned previously, BTV-14 emerged in Eastern Europe in 2011 (in Smolensk, Russia) and spread to the West causing BTV outbreaks in Lithuania and Poland in the subsequent years $(10,13)$. In Poland the virus was circulating from September 2012 to October 2014.

Conflict of Interests Statements: The authors declare that there is no conflict of interests regarding the publication of this article.

Financial Disclosure Statement: The research was financed with the funds of the National Veterinary Research Institute in Pulawy, Poland.

Animal Rights Statement: None required.

\section{References}

1. Anthony S., Jones H., Darpel K.E., Elliot H., Maan S., Samuel A., Mellor P.S, Mertens, P.P.C.: A duplex RT-PCR assay for detection of genome segment 7 (VP7 gene) from 24 BTV serotypes. J Virol Methods 2007, 141, 188-197.

2. DeMaula C.D., Bonneau K.R., MacLachlan N.J.: Changes in the outer capsid protein of bluetongue virus serotype 10 that abrogate neutralization by monoclonal antibodies. Virus Res 2000, 67, 59-66.

3. Elbers A.R., Backx A., Ekker H.M., van der Spek A.N., van Rijn, P.A.: Performance of clinical signs to detect bluetongue virus serotype 8 outbreaks in cattle and sheep during the 2006-epidemic in the Netherlands. Vet Microbiol 2008, 129, $156-162$.

4. Erasmus B.J.: Bluetongue virus. In: Virus infections of ruminants. edited by Dinter Z., Morein B., Elsevier Science Publisher, New York, 1990, pp. 227-237.

5. Eschbaumer M., Wäckerlin R., Savini G., Zientara S., Sailleau C., Bréard E., Beer M., Hoffmann B.: Contamination in bluetongue virus challenge experiments. Vaccine 2011, 29, 4299-4301.

6. Flannery J.: Current BT situation and work of the EURL. EU Bluetongue Virus and African Horse Sickness Virus Reference Laboratory Workshop 2015. Ascot. 24-25 November 2015.

7. Hoffmann B., Sasserath M., Thalheim S., Bunzenthal C., Strebelow G., Beer M.: Bluetongue virus serotype 8 reemergence in Germany, 2007 and 2008. Emerg Infect Dis 2008, 14, 1421-1423.

8. Maan N.S., Maan S., Belaganahalli M.N., Ostlund E.N., Johnson D.J., Nomikou K., Mertens, P.P.C.: Identification and differentiation of the twenty six bluetongue virus serotypes by RT-PCR amplification of the serotype-specific genome segment 2. Plos One 2012, 7, 1-9.

9. Maan S., Maan N.S., Belaganahalli M.N., Rao P.P., Singh K.P., Hemadri D., Putty K., Kumar A., Batra K., Krishnajyothi Y.,
Chandel B.S., Reddy G.H., Nomikou K., Reddy Y.N., Attoui H., Hegde N.R., Mertens, P.P.C.: Full-genome sequencing as a basis for molecular epidemiology studies of bluetongue virus in India. PLoS One 2015, doi: 10.1371/journal.pone.0131257. eCollection 2015.

10. Nomikou K., Batten C., Morecroft E., Vigo Martin M., Kolbasov D., Frost L., Mertens P.: Molecular characterization of BTV-14 in North Europe. Bluetongue and related Orbiviruses. IV international Conference. Rome, 5-7 November 2014.

11. Nomikou K., Hughes J., Wash R., Kellam P., Bréard E., Zientara S., Palmarini M., Biek R., Mertens P.: Widespread reassortment shapes the evolution and epidemiology of bluetongue virus following European invasion. Plos Pathogens 2015, doi:10.1371/journal.ppat.1005056.

12. Nomikou K., Maan S., Batten C., Mertens P.: Bluetongue Molecular Epidemiology Report 30 November 2012: Poland. VBD Molecular Epidemiology Report Form (201302-08). Available at: http://ec.europa.eu/food/animal/diseases/ controlmeasures/docs/bluetongue_molecular_epidemiology_repo rt_30112012_poland.pdf.

13. Orłowska A., Trębas P., Smreczak M., Marzec A., Żmudziński J.F.: First detection of bluetongue virus serotype 14 in Poland. Arch Virol 2016, doi: 10.1007/s00705-016-2857-0.

14. Rao P.P., Reddy Y.N., Ganesh K., Nair S.G., Niranjan V., Hegde N.R.: Deep sequencing as a method of typing bluetongue virus isolates. J Virol Methods 2013, 193, 314-319.

15. Ratinier M., Caporale M., Golder M., Franzoni G., Allan K., Nunes S.F., Armezzani A., Bayoumy A., Rixon F., Shaw A., Palmarini M.: Identification and characterization of a novel nonstructural protein of bluetongue virus. PLoS Pathog 2013, doi: 10.1371/journal.ppat.1002477.

16. Ruiz-Fons F., Sánchez-Matamoros A., Gortázar C., SánchezVizcaíno J.M.: The role of wildlife in bluetongue virus maintenance in Europe: lessons learned after the natural infection in Spain. Virus Res 2014, 182, 50-58.

17. Schulz C., Bréard E., Sailleau C., Jenckel M., Viarouge C., Vitour D., Palmarini M., Gallois M., Höper D., Hoffmann B., Beer M., Zientara S.: Bluetongue virus serotype 27: detection and characterization of two novel variants in Corsica, France. J Gen Virol 2016, doi: 10.1099/jgv.0.000557.

18. Shaw A.E., Montaghan P., Alpar H.O., Anthony S., Darpel K.E., Batten C.A., Guercio A., Alimena G., Vitale M., Bankowska K., Carpenter S., Jones H., Oura C.A.L., King D.P., Elliott H., Mellor P.S., Mertens P.P.C.: Development and initial evaluation of a real-time RT-PCR assay to detect bluetongue virus genome segment 1. J Virol Methods 2007, 145, 115-126.

19. Shaw A.E., Ratinier M., Nunes S.F., Nomikou K., Caporale M., Golder M., Allan K., Hamers C., Hudelet P., Zientara S., Bréard E., Mertens P., Palmarini M.: Reassortment between two serologically unrelated bluetongue virus strains is flexible and can involve any genome segment. J Virol. 2013, 87, 543-557.

20. Stram Y., Bumbarov V., Golender N., Brenner J.: BTV in Israel. EU Bluetongue Virus and African Horse Sickness Virus Reference Laboratory Workshop, 2015. Ascot. 24-25 November 2015.

21. Tamura K., Dudley J., Nei M., Kumar S.: MEGA4: Molecular evolutionary genetics analysis (MEGA) software version 4.0. Mol Biol Evol 2007, 24, 1596-1599.

22. Toussaint J.F., Vandenbussche F., Mast J.D., De Meester L., Goris N., Van Dessel W., Vanopdenbosche E., Kerkhofs P., Zientara S., Sailleau C., Czaplicki G., Depoorter G., Dochy J.M., De Clercq K.: Bluetongue in northern Europe. Vet Rec 2006, $159,327$.

23. Trębas P., Smreczak M., Orłowska A., Żmudziński J.F.: Bluetongue epizootiology. Med Weter 2007, 63, 1273-1276.

24. Zientara S., Sancheaz-Vizcaíno J.M.: Control of bluetongue in Europe. Vet Microbiol 2013, 165, 33-37. 